\title{
Effects of SEBS-g-MAH on the properties of injection moulded poly(lactic acid)/nano-calcium carbonate composites
}

\author{
W. S. Chow ${ }^{1,2,3^{*}}$, Y. Y. Leu ${ }^{1}$, Z. A. Mohd Ishak ${ }^{1,2}$ \\ ${ }^{1}$ School of Materials and Mineral Resources Engineering, Engineering Campus, Universiti Sains Malaysia, Nibong Tebal \\ 14300 Penang, Malaysia \\ ${ }^{2}$ Cluster for Polymer Composites, Engineering and Technology Research Platform, Engineering Campus, Universiti Sains \\ Malaysia, 14300 Nibong Tebal, Pulau Pinang, Malaysia \\ ${ }^{3}$ Institut für Verbundwerkstoffe $\mathrm{GmbH}$ (Institute for Composite Materials), Kaiserslautern University of Technology, \\ D-67663 Kaiserslautern, Germany
}

Received 8 November 2011; accepted in revised form 15 January 2012

\begin{abstract}
Poly(lactic acid)/nano-precipitated calcium carbonate (PLA/NPCC) composites toughened with maleated styrene-ethylene/butylene-styrene (SEBS-g-MAH) were prepared by melt-compounding on a co-rotating twin-screw extruder followed by injection moulding. The mechanical properties of the PLA nanocomposites were characterized by tensile, flexural and impact tests, while their morphology were investigated using transmission electron microscopy (TEM). The thermal properties of the composites were examined with differential scanning calorimeter (DSC) and thermogravimetric analyzer (TGA). The elongation at break and impact strength of the PLA/NPCC nanocomposites increased significantly after addition of SEBS-g-MAH. Both nano-dispersed NPCC and small NPCC clusters were found in PLA matrix. Also, some SEBS-g-MAH encapsulated NPCC can be observed. Thermal stability of PLA/NPCC was enhanced prominently by the addition of SEBS-g-MAH.
\end{abstract}

Keywords: nanocomposites, poly(lactic acid), nano-precipitated calcium carbonate, thermal properties, mechanical properties

\section{Introduction}

Organic/inorganic hybrid nanocomposites have received significant attentions from both academic and industrial sectors due to the excellent enhancement in certain physical and chemical properties compared to the pure material. The addition of nanofillers such as nanoclays, nano-calcium carbonate and nano-silica improve the mechanical performance of polymers significantly [1-3]. The addition of inorganic fillers has been proved to be an effective approach for the enhancement of the mechanical properties (e.g. stiffness and toughness). Nanoand micro-sized calcium carbonate $\left(\mathrm{CaCO}_{3}\right)$ particles have been used to improve the impact tough- ness of several thermoplastics, e.g. polypropylene, polyethylene and aliphatic polyketone [4-7].

Poly(lactic acid) (PLA) derived from renewable resources has become popular owing to their sustainability, biodegradability and superior transparency [8]. In recent reports, PLA-based nanocomposites, prepared by the addition of nanofillers such as nanoclay, nano-calcium carbonate, titanium oxide nanoparticles, cellulose nanofiber and carbon nanotube, exhibited remarkable improvement in mechanical and thermal properties, dimensional stability, barrier and physicochemical behaviours [9-13].

Though the hybridization of polymer and nanoparticle can be a potential class of materials, there are

\footnotetext{
${ }^{*}$ Corresponding author, e-mail: shyang@eng.usm.my
}

(c) BME-PT 
few issues always need to be considered, e.g. compatibility between polymer and nanoparticles, dispersion and distribution of nanoparticles, brittleness and toughness of the polymer nanocomposites, as well as their processability. Therefore, chemical and physical modifications are often applied to achieve these objectives. Maleic anhydride grafted styrene-ethylene/butylene-styrene copolymers (SEBS-g-MAH) has been used as polymeric compatibilizer, interfacial modifier and toughening agent. In our previous work, the impact strength, elongation at break and thermal stability of PLA/organo-montmorillonite nanocomposites was enhanced significantly by the addition of SEBS-g-MAH [14]. SEBS-g-MAH improved the dispersion of nano-magnesium hydroxide $(\mathrm{MH})$ and interfacial adhesion in polypropylene/MH nanocomposites [15]. The impact strength and ductility of polyamide 6/polypropylene/organoclay nanocomposites was improved significantly by the addition of SEBS-g-MAH [16]. Super-tough polyamide 6/organo-montmorillonite nanocomposite was obtained with $30 \mathrm{wt} \%$ of maleinated styreneethylene/butylene-styrene copolymers [17]. It has also been documented that the essential work of fracture for high density polyethylene/organo-montmorillonite and polypropylene/organo-montmorillonite were improved in the presence of SEBS [18]. The goal of present work is to improve the thermal and mechanical properties (especially elongation at break and impact strength) of PLA/NPCC nanocomposites by incorporation of SEBS-g-MAH. For this purpose, PLA/NPCC nanocomposites with and without SEBS-g-MAH were produced using melt mixing followed by injection moulding. Accordingly, the mechanical and thermal properties of the PLA nanocomposites were determined and discussed.

\section{Experimental}

\subsection{Materials}

PLA (Ingeo ${ }^{\text {TM }}$ 3051D) was purchased from NatureWorks LLC ${ }^{\circledR}$ (Minnetonka, USA). The specific gravity and melt flow index of the PLA are 1.25 and $25 \mathrm{~g} / 10 \mathrm{~min}\left(2.16 \mathrm{~kg}\right.$ load, $\left.210^{\circ} \mathrm{C}\right)$. The stearic acid treated NPCC (Zancarb CC-R; particle size: 40$80 \mathrm{~nm}$; specific gravity: 2.50) was supplied by Zantat Sdn. Bhd (Kuala Lumpur, Malaysia). SEBS-gMAH with a MAH grafting level of 1.4-2.0 wt\%
Table 1. Materials designation and composition for PLA/ NPCC composites

\begin{tabular}{|l|c|c|c|}
\hline \multirow{2}{*}{$\begin{array}{c}\text { Materials } \\
\text { designation }\end{array}$} & \multicolumn{3}{|c|}{ Composition } \\
\cline { 2 - 4 } & $\begin{array}{c}\text { PLA } \\
{[\mathbf{w t} \% \mathbf{0}]}\end{array}$ & $\begin{array}{c}\text { NPCC } \\
{[\mathbf{w t} \% \mathbf{\%}}\end{array}$ & $\begin{array}{c}\text { SEBS-g-MAH } \\
\text { [phr] }\end{array}$ \\
\hline PLA & 100 & - & - \\
\hline PLA/NPCC & 98 & 2 & - \\
\hline PLA/NPCC/S5 & 98 & 2 & 5 \\
\hline PLA/NPCC/S10 & 98 & 2 & 10 \\
\hline PLA/NPCC/S15 & 98 & 2 & 15 \\
\hline PLA/NPCC/S20 & 98 & 2 & 20 \\
\hline
\end{tabular}

and styrene/rubber ratio of 30/70 (wt/wt) was purchased from Shanghai Jianqiao Plastic Co. Ltd., (Shanghai, China). The melt flow index and specific gravity of the SEBS-g-MAH are $1.0 \mathrm{~g} / 10 \mathrm{~min}$ $\left(2.16 \mathrm{~kg}\right.$ load, $\left.230^{\circ} \mathrm{C}\right)$ and 0.91 , respectively. The designation and composition for PLA/NPCC nanocomposites are shown in Table 1.

\subsection{Preparation of PLA/NPCC nanocomposites}

Prior to extrusion, all the materials were dried at $80^{\circ} \mathrm{C}$ for $15 \mathrm{~h}$ in vacuum oven (Memmert $\mathrm{GmbH}$, Schwabach, Germany). PLA nanocomposites were melt-compounded using a PSM30 co-rotating twinscrew extruder (Sino-Alloy Machinery, Taoyuan County, Taiwan) with temperature zone set up in the range of $160-190^{\circ} \mathrm{C}$. The screw speed was set at $150 \mathrm{rpm}$. PLA nanocomposite specimens [tensile (ASTM D638 type I), flexural (ASTM D790) and impact (ASTM D4812)], were moulded using an injection moulding machine (HTF86X1, Haitian Plastics Machinery, Ningbo, China). The barrel temperatures were set in the range of $165-190^{\circ} \mathrm{C}$, from the feeding section to the nozzle.

\subsection{Transmission electron microscopy (TEM)}

TEM specimens of PLA nanocomposites were prepared using a PT-PC PowerTome ultramicrotome (Boeckeler Instruments, Arizona, USA). Ultra-thin sections of about $50 \mathrm{~nm}$ in thickness of the PLA specimen was cut with a diatome diamond knife $\left(45^{\circ}\right)$ at room temperature. The specimen was stained with osmium tetroxide for an hour prior TEM measurements. TEM measurements were conducted using a Zeiss Libra 120 Plus energy filtering transmission electron microscope (Carl Zeiss, Jena, Germany) operating at an accelerating voltage of $120 \mathrm{kV}$. 


\subsection{Thermal characterization (TGA and DSC)}

Thermal decomposition temperature of the PLA nanocomposites was characterized using a Pyris 6 thermogravimetric analyzer (Perkin Elmer, Massachusetts, USA). The specimens were heated from room temperature to $600^{\circ} \mathrm{C}$ at a heating rate of $10^{\circ} \mathrm{C} / \mathrm{min}$ in nitrogen atmosphere. Differential scanning calorimeter DSC 6 (Perkin Elmer, Massachusetts, USA) was used to evaluate the thermal behaviour of the PLA/NPCC nanocomposite. The specimens were scanned from 30 to $190^{\circ} \mathrm{C}$ at a heating rate of $10^{\circ} \mathrm{C} / \mathrm{min}$. Then, they were cooled from 190 to $30^{\circ} \mathrm{C}$ at a cooling rate of $10^{\circ} \mathrm{C} / \mathrm{min}$. Second scanning was performed similar to the first scanning in order to erase the thermal history. The glass transition temperature $\left(T_{\mathrm{g}}\right)$, melting temperature $\left(T_{\mathrm{m}}\right)$, and crystallization temperature $\left(T_{\mathrm{c}}\right)$ were determined. The degree of crystallinity $\left(\chi_{\mathrm{c}}\right)$ of PLA nanocomposites was calculated according to Equation (1):

$\chi_{\mathrm{c}}=\frac{\Delta H_{\mathrm{m}}}{\Delta H_{\mathrm{f}} \cdot w_{\mathrm{PLA}}} \cdot 100 \%$

where $\chi_{\mathrm{c}}$ is the degree of crystallinity; $\Delta H_{\mathrm{m}}$ is the heat of fusion of the sample; $\Delta H_{\mathrm{f}}$ corresponds to the heat of fusion for $100 \%$ crystalline material, and $w_{\text {PLA }}$ is the net weight fraction of the PLA. The heat of fusion of $100 \%$ crystalline PLA $\left(\Delta H_{\mathrm{f}}\right)$ is approximately $93.6 \mathrm{~J} / \mathrm{g}[19]$.

\subsection{Mechanical testing}

Tensile and flexural tests were performed using an Instron 3366 (Instron, Massachusetts, USA) according to ASTM D638 and ASTM D790, respectively. Tensile tests were conducted at a crosshead speed of $5 \mathrm{~mm} / \mathrm{min}$. Flexural tests were performed using three-point bending configuration at crosshead speed of $1.5 \mathrm{~mm} / \mathrm{min}$ and support span length of
$50 \mathrm{~mm}$. Charpy impact test was carried out on both notched and un-notched specimens using a Zwick analogue Charpy Pendulum Impact Tester (Zwick Roell, Ulm, Germany) with a pendulum of $7.5 \mathrm{~J}$.

\section{Results and discussion}

\subsection{Transmission electron microscopy (TEM)}

Figure 1a-1f shows the TEM images of the PLA/ NPCC composites (with and without SEBS-g-MAH) taken at low and high magnification. It can be seen that the NPCC nanoparticles are in cubic shape with dimension of 40-80 nm. Nano-dispersed NPCC and small clusters of NPCC can be observed in the PLA matrix (c.f. Figure 1a-1b). In Figure 1c and 1e, the dark grey region (i.e. region that stained by osmium tetroxide) with dimension of approximately $1-2 \mu \mathrm{m}$ can be ascribed to the SEBS-gMAH. Interesting to note that some of the NPCC are encapsulated by SEBS-g-MAH (c.f. Figure 1d and 1f), which can be associated to the affinity between NPCC and SEBS-g-MAH. Also, one may find that more NPCC were encapsulated by SEBSg-MAH for the PLA/NPCC composites which contain higher loading of SEBS-g-MAH (i.e. PLA/ NPCC/S20).

\subsection{Thermogravimetric analysis (TGA)}

TGA curves for NPCC, SEBS-g-MAH, PLA and PLA/NPCC/SEBS-g-MAH composites are displayed in Figure 2. The decomposition temperatures, $T_{95}, T_{50}$ and $T_{5}$ are summarized in Table 2. $T_{95}, T_{50}$ and $T_{5}$ are corresponding to the temperature at which the remaining mass of the materials is 95 , 50 and $5 \%$ respectively. The decomposition temperature in the range of $335-362^{\circ} \mathrm{C}$ is related to the thermal dissociation of the PLA. From the TGA curves, it can be seen that the decomposition temperature of NPCC starts at $250^{\circ} \mathrm{C}$ and the char residue is approximately $96.9 \%$ at the temperature

Table 2. TGA data of PLA and PLA/NPCC composites

\begin{tabular}{|c|c|c|c|c|c|c|}
\hline \multirow{2}{*}{ Materials designation } & \multicolumn{2}{|c|}{ Decomposition temperature $\left[{ }^{\circ} \mathrm{C}\right]$} & \multirow{2}{*}{$\begin{array}{c}\mathbf{T}_{95} \\
{\left[{ }^{\circ} \mathbf{C}\right]}\end{array}$} & \multirow{2}{*}{$\begin{array}{c}\mathbf{T}_{50} \\
{\left[{ }^{\circ} \mathbf{C}\right]}\end{array}$} & \multirow{2}{*}{$\begin{array}{c}\mathbf{T}_{5} \\
{\left[{ }^{\circ} \mathbf{C}\right]}\end{array}$} & \multirow{2}{*}{$\begin{array}{c}\text { Char residue } \\
{[\%]}\end{array}$} \\
\hline & $\mathbf{T}_{\mathrm{d} 1}$ & $\mathbf{T}_{\mathrm{d} 2}$ & & & & \\
\hline PLA & 353.4 & - & 346.0 & 370.0 & 390.8 & 0 \\
\hline PLA/NPCC & 334.6 & - & 327.2 & 352.4 & 376.9 & 2.8 \\
\hline PLA/NPCC/S5 & 354.7 & 446.0 & 337.1 & 368.7 & 464.8 & 2.7 \\
\hline PLA/NPCC/S10 & 359.1 & 451.0 & 342.8 & 372.7 & 483.8 & 2.8 \\
\hline PLA/NPCC/S15 & 360.8 & 451.7 & 343.7 & 374.7 & 486.9 & 2.2 \\
\hline PLA/NPCC/S20 & 361.9 & 451.6 & 345.3 & 375.2 & 493.7 & 2.3 \\
\hline NPCC & 250.0 & - & - & - & - & 96.9 \\
\hline SEBS-g-MAH & 444.0 & - & 424.8 & 469.9 & 498.9 & 0 \\
\hline
\end{tabular}




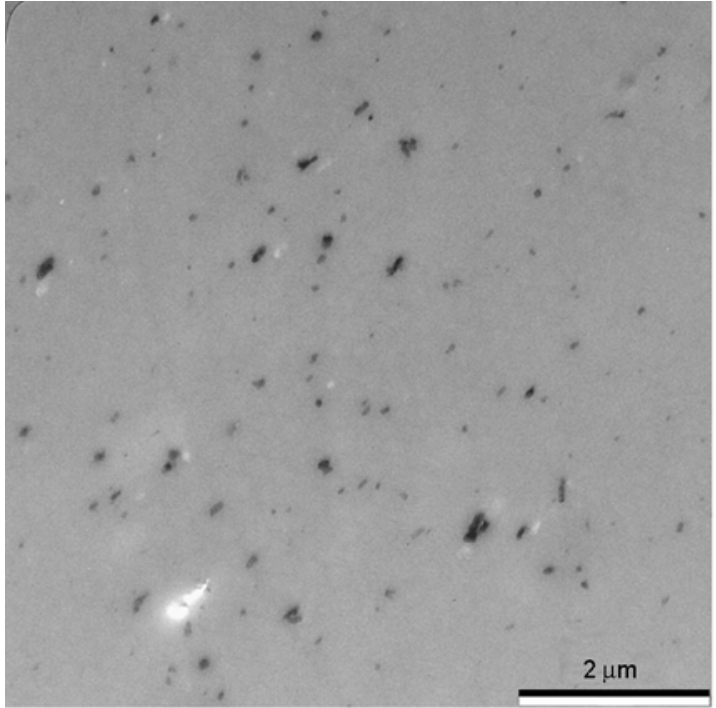

a)

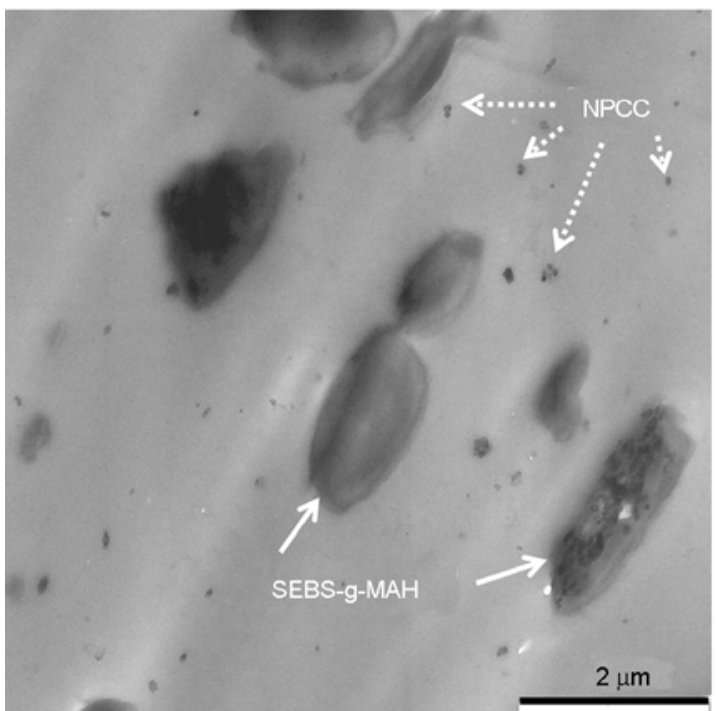

c)

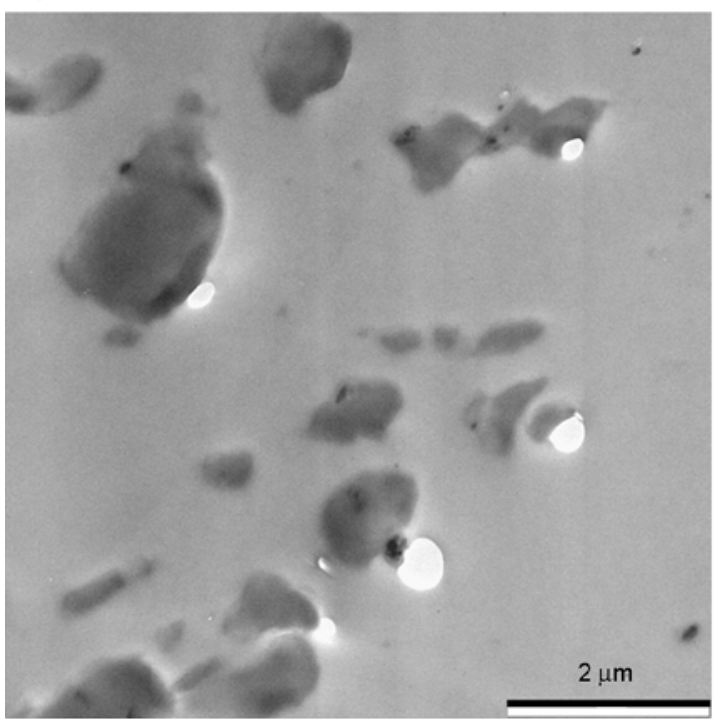

e)

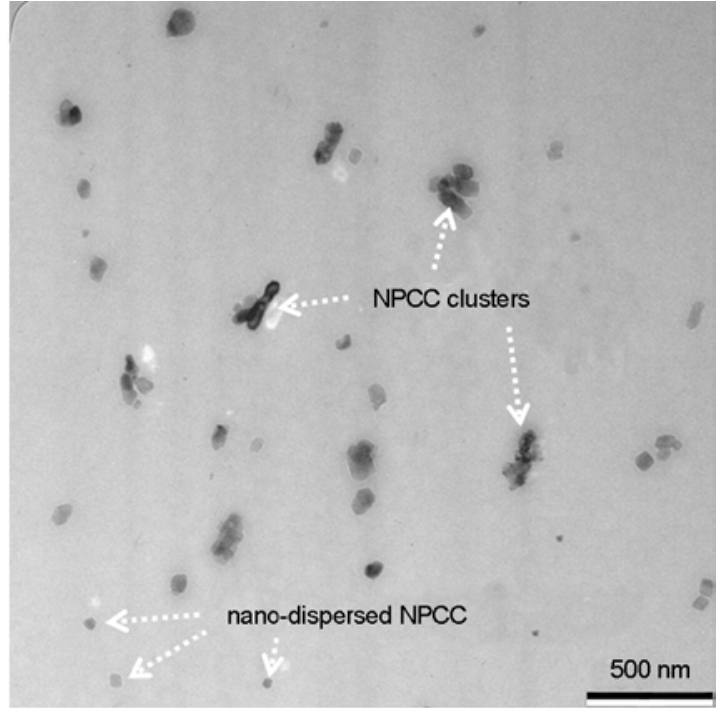

b)

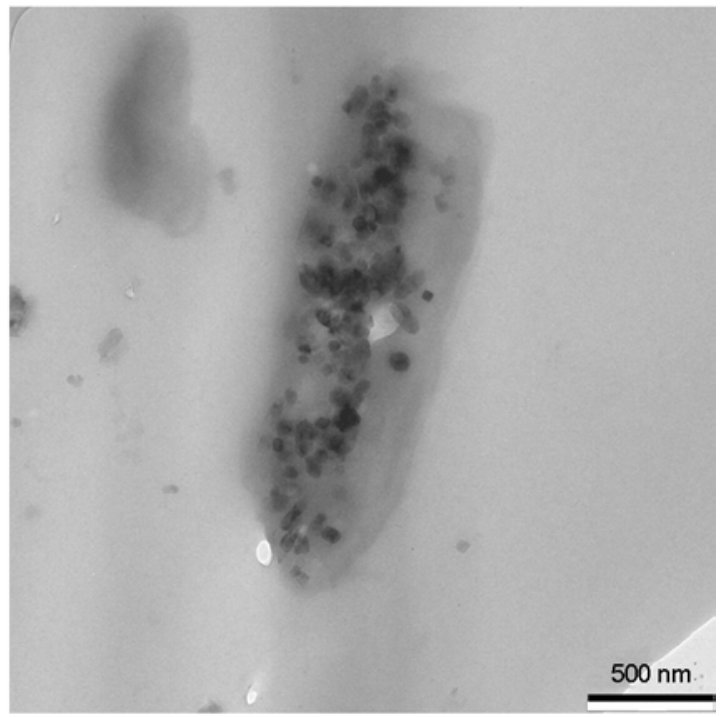

d)

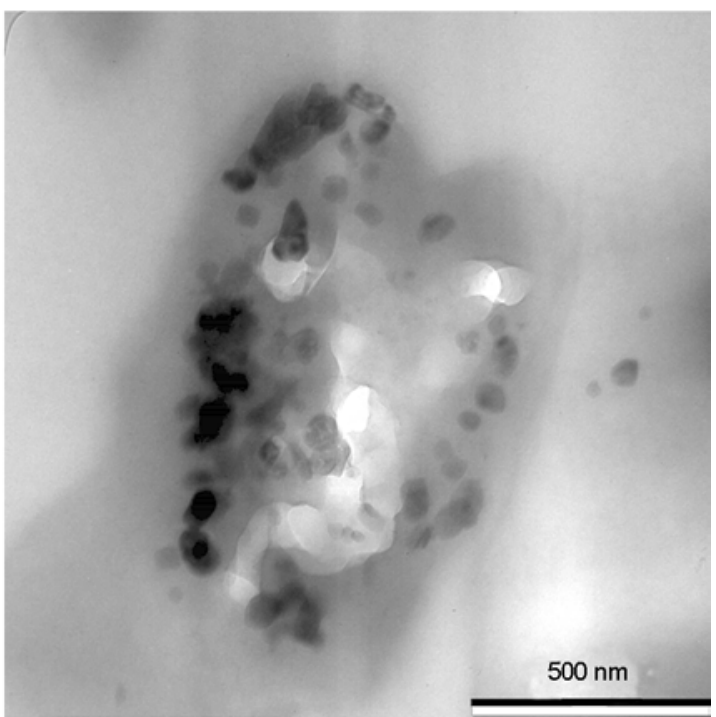

f)

Figure 1. a) TEM image of PLA/NPCC composites taken at low magnification, b) TEM image of PLA/NPCC composites taken at high magnification, c) TEM image of PLA/NPCC/S5 composites taken at low magnification, d) TEM image of PLA/NPCC/S5 composites taken at high magnification, e) TEM image of PLA/NPCC/S20 composites taken at low magnification, f) TEM image of PLA/NPCC/S20 composites taken at high magnification. 


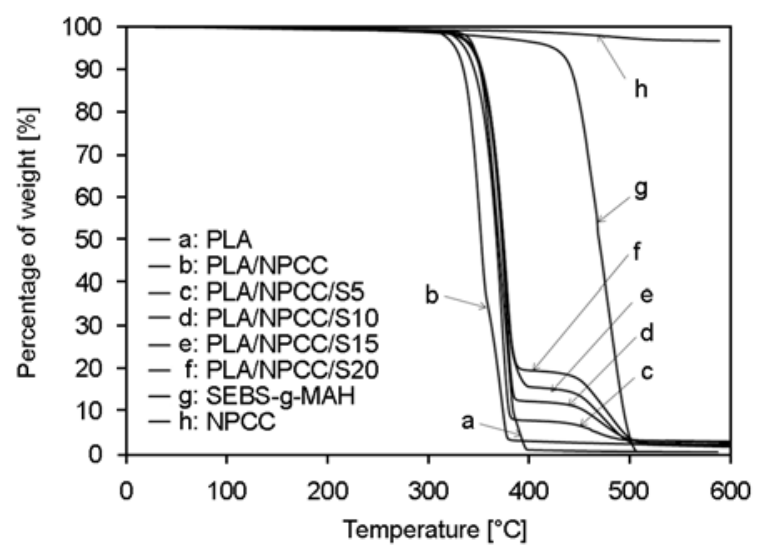

Figure 2. TGA curves of PLA, NPCC, SEBS-g-MAH and PLA/NPCC composites

of $600^{\circ} \mathrm{C}$. The mass loss of NPCC is attributed to the decomposition of stearic acid (i.e. surface modifier). It is also found that the decomposition of organic modifier may accelerate thermal decomposition for the PLA/NPCC composites. According to Kim and Michler [20], the basic nature of calcium carbonate may catalyze the depolymerisation of the ester bonds of PLA which led to a decrease in thermal stability of the respective composite. It can be seen that the decomposition temperatures, $T_{95}, T_{50}$ and $T_{5}$ values of PLA/NPCC nanocomposites improved significantly by the addition of SEBS-g-MAH. Note that the highest mass loss of SEBS-g-MAH occurred at temperature of approximately $444^{\circ} \mathrm{C}$. Also, the thermal stability of PLA/NPCC nanocomposites increased marginally with the increasing loading of SEBS-g-MAH. Similar finding was also observed in our previous works on PLA/OMMT [14] and PA6/PP/organoclay nanocomposites [16].

\subsection{Differential scanning calorimetry (DSC)}

Figure 3 shows the DSC thermograms of PLA and PLA/NPCC nanocomposites. The thermal characteristics (e.g. $T_{\mathrm{g}}, T_{\mathrm{c}}, T_{\mathrm{m}}$ ) of the PLA and its nanocomposites are summarized in Table 3. In Figure 3, PLA shows a melting temperature peak $\left(T_{\mathrm{m} 1}\right)$ at $168.8^{\circ} \mathrm{C}$ with a shoulder peak $\left(T_{\mathrm{m} 2}\right)$ at $161.2^{\circ} \mathrm{C}$.

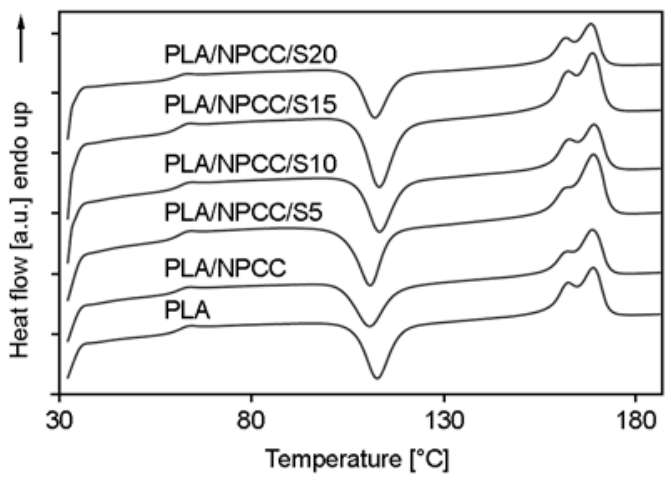

Figure 3. DSC thermograms of PLA and PLA/NPCC composites

Bimodal melting peaks are observed in all PLA/ NPCC composites with and without SEBS-g-MAH. Multiple melting behaviour of PLA is depends on crystallization conditions (thermal prehistory) and $T_{\mathrm{c}}$ value [21]. Double melting endotherms are commonly found in PLA which crystallized at $T_{\mathrm{c}}$ in the temperature range of $110-130^{\circ} \mathrm{C}$ [22]. The multiple melting endotherms can be attributed to the meltrecrystallization mechanism [23]. From Table 3, it can be seen that, the presence of NPCC does not changes the $T_{\mathrm{g}}, T_{\mathrm{c}}, T_{\mathrm{m} 1}$ and $T_{\mathrm{m} 2}$ values of PLA significantly, this may related to the weak interaction between the polymer and the mineral filler [24]. However, PLA/NPCC nanocomposite exhibits higher degree of crystallinity than that of neat PLA. Such behaviour is reasonable due to the fact that NPCC can act as nucleating agent. Similar finding was reported by Suksut and Deeprasertkul [25], who found that the degree of crystallinity of PLA was increased prominently in the presence of $\mathrm{CaCO}_{3}$. On the contrary, the incorporation of SEBS-g-MAH reduces the degree of crystallinity of PLA/NPCC nanocomposites. This is attributed to the encapsulation of NPCC by SEBS-g-MAH (evidenced by TEM, as discussed previously), which may retard the efficiency of NPCC as nucleating agent in the crystallization of PLA. This is in line with the finding from Tjong et al. [1], who reported that SEBS-

Table 3. Thermal characteristics of PLA and PLA/NPCC composites recorded from DSC

\begin{tabular}{|c|c|c|c|c|c|c|c|}
\hline \multirow{2}{*}{ Materials designation } & \multicolumn{7}{|c|}{ Thermal characteristics } \\
\hline & $\mathbf{T}_{\mathrm{g}}\left[{ }^{\circ} \mathbf{C}\right]$ & $\mathbf{T}_{\mathrm{c}}\left[{ }^{\circ} \mathbf{C}\right]$ & $\mathbf{T}_{\mathrm{m} 1}\left[{ }^{\circ} \mathbf{C}\right]$ & $\mathbf{T}_{\mathrm{m} 2}\left[{ }^{\circ} \mathbf{C}\right]$ & $\Delta \mathbf{H}_{\mathbf{c}}[\mathbf{J} / \mathbf{g}]$ & $\Delta \mathbf{H}_{\mathrm{m}}[\mathbf{J} / \mathbf{g}]$ & $\chi_{c}[\%]$ \\
\hline PLA & 60.9 & 112.7 & 168.8 & 161.2 & 27.3 & 31.2 & 33.3 \\
\hline PLA/NPCC & 60.6 & 110.8 & 168.6 & 160.1 & 33.3 & 34.9 & 38.0 \\
\hline PLA/NPCC/S5 & 60.8 & 110.8 & 169.0 & 160.2 & 24.8 & 32.2 & 36.8 \\
\hline PLA/NPCC/S10 & 61.3 & 113.3 & 169.1 & 163.2 & 24.7 & 28.0 & 33.5 \\
\hline PLA/NPCC/S15 & 60.6 & 113.2 & 168.7 & 162.0 & 27.5 & 29.1 & 36.4 \\
\hline PLA/NPCC/S20 & 59.7 & 112,5 & 168.2 & 161.0 & 21.3 & 24.9 & 32.5 \\
\hline
\end{tabular}


g-MAH reduced the degree of crystallinity of polypropylene/montmorillonite nanocomposites.

\subsection{Mechanical properties}

The tensile stress-strain curves of neat PLA and PLA/NPCC composites are shown in Figure 4. PLA fractured in brittle mode with $8.4 \%$ elongation at break. It can be seen that PLA/NPCC nanocomposite achieved $12.4 \%$ of elongation at break, which suggesting an improvement in ductility of the material. Furthermore, PLA/NPCC/SEBS-g-MAH composites experienced significant cold drawing and yielding implying that further enhancement in ductility of the nanocomposites. Mechanical properties of PLA and PLA/NPCC nanocomposites are summarized in Table 4. It can be seen that the NPCC does not have significant effect on the tensile and flexural modulus of PLA. This is due to the nonreinforcing behaviour of this NPCC. However, the elongation at break of PLA increased of about $48 \%$ by the addition of NPCC, implying an improvement in toughness of PLA. This is due to the fact that NPCC can act as stress concentrator and induce microvoids by debonding at the NPCC-PLA interface during the tensile deformation. The cavita-

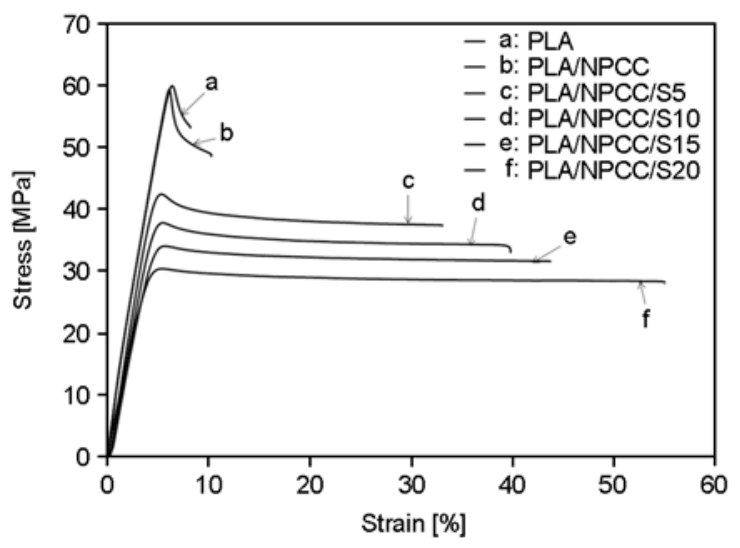

Figure 4. Stress-strain curves of PLA and PLA/NPCC composites tional process promotes shear-banding mechanism in the plane-stress region and triggers matrix shearing in PLA during fracture. Accordingly, the shear yielding mechanism becomes operative and the PLA composites are able to absorb large quantities of energy when subjected to fracture deformation. This is in line with the micro-mechanistic model for toughening using filler particles as proposed by Kim and Michler [20]. According to Weon et al. [26], toughenability of PP has been positively altered by the incorporation of calcium carbonate, which is also related to the massive crazing and shear banding of the PP matrix in the presence of the filler. From Table 4, it can be seen that the modulus and strength of PLA/NPCC composites reduced marginally with the increasing content of SEBS-gMAH. This is attributed to the lower modulus and elastomeric nature of SEBS-g-MAH [1, 17, 27]. Note that the elongation at break of PLA/NPCC composites increased drastically with increasing loading of SEBS-g-MAH. SEBS-g-MAH acts as stress concentrators upon the application of tensile stress and formed micro-voids that able to trigger micro-deformation mechanisms. This will lead to an increase of ductility and toughness in the nanocomposites.

The Charpy impact strength for notched and unnotched specimens of neat PLA and PLA/NPCC nanocomposites are summarized in Table 4 . The impact strength for both notched and un-notched PLA/NPCC nanocomposite increased significantly by the incorporation of SEBS-g-MAH. The impact strength of PLA/NPCC nanocomposite increased 268 and $138 \%$ for un-notched and notched specimens, respectively with the addition of $20 \mathrm{phr}$ of SEBS-g-MAH. According to Collyer [28], the toughening mechanism of rubber particles dispersed within a glassy polymer includes energy absorption

Table 4. Mechanical properties of PLA and PLA/NPCC composites

\begin{tabular}{|c|c|c|c|c|c|c|}
\hline \multirow{2}{*}{ Mechanical properties } & \multicolumn{6}{|c|}{ Materials designation } \\
\hline & PLA & PLA/NPCC & PLA/NPCC/S5 & PLA/NPCC/S10 & PLA/NPCC/S15 & PLA/NPCC/S20 \\
\hline Tensile modulus [GPa] & $1.2 \pm 0.02$ & $1.2 \pm 0.03$ & $1.1 \pm 0.03$ & $1.0 \pm 0.01$ & $0.9 \pm 0.02$ & $0.9 \pm 0.03$ \\
\hline Tensile strength [MPa] & $59.4 \pm 0.4$ & $58.7 \pm 1.3$ & $36.9 \pm 0.5$ & $33.7 \pm 0.5$ & $30.5 \pm 1.1$ & $27.7 \pm 0.3$ \\
\hline Elongation at break [\%)] & $8.4 \pm 0.2$ & $12.4 \pm 2.1$ & $32.6 \pm 1.7$ & $42.9 \pm 2.0$ & $44.0 \pm 0.3$ & $56.8 \pm 1.8$ \\
\hline Flexural modulus [GPa] & $3.6 \pm 0.1$ & $3.8 \pm 0.1$ & $3.5 \pm 0.1$ & $3.2 \pm 0.1$ & $2.8 \pm 0.1$ & $2.5 \pm 0.1$ \\
\hline Flexural strength [MPa] & $97.0 \pm 0.2$ & $96.1 \pm 1.5$ & $81.2 \pm 1.2$ & $68.8 \pm 0.5$ & $63.3 \pm 1.1$ & $55.4 \pm 1.3$ \\
\hline $\begin{array}{l}\text { Impact strength }\left[\mathrm{kJ} / \mathrm{m}^{2}\right] \\
\text { [Un-notched] }\end{array}$ & $22.6 \pm 1.5$ & $22.5 \pm 1.0$ & $38.6 \pm 1.5$ & $51.7 \pm 0.55$ & $73.5 \pm 2.0$ & $82.9 \pm 1.4$ \\
\hline $\begin{array}{l}\text { Impact strength }\left[\mathrm{kJ} / \mathrm{m}^{2}\right] \\
\text { [Notched] }\end{array}$ & $4.0 \pm 0.6$ & $3.2 \pm 0.9$ & $6.0 \pm 0.7$ & $6.4 \pm 0.5$ & $6.6 \pm 0.3$ & $7.6 \pm 1.1$ \\
\hline
\end{tabular}


by rubber particles, debonding at the rubber-matrix interface, matrix crazing, shear yielding or a combination of shear yielding and crazing. Upon the application of impact stress, the rubber particles in the composite acted as stress concentrators and cavitate and/or debond at the rubber-matrix interface, leading to a relief of the triaxial stress state ahead of the notch or crack, thus creating a stress state beneficial for the initiation of multiple matrix shear yielding [29].

\section{Conclusions}

The PLA/NPCC nanocomposites were successfully produced by using melt compounding technique. Nano-dispersed NPCC (ca. $40 \mathrm{~nm}$ ) and small NPCC clusters (containing 3-6 NPCC particles) were distributed in PLA matrix. Also, NPCC can act as nucleating agent for PLA. However, NPCC does not enhance the modulus and strength of PLA. It was also found that the thermal stability of PLA/ NPCC is lower than that of PLA. SEBS-g-MAH encapsulated NPCC may suppress the nucleating effects of NPCC. The main objectives of this works have been achieved, i.e. (1) significant enhancement of elongation at break and impact strength of PLA/NPCC nanocomposites, and (2) the thermal stability of PLA/NPCC/SEBS-g-MAH is higher than that of PLA/NPCC nanocomposites.

\section{Acknowledgements}

Authors would like to thank Universiti Sains Malaysia for the Research University (RU) Grant (814070), Incentive Grant (8021013) and USM Postgraduate Research Grant Scheme (USM-RU-PGRS 8033002) financial support.

\section{References}

[1] Tjong S. C., Bao S. P., Liang G. D.: Polypropylene/ montmorillonite nanocomposites toughened with SEBS-g-MA: Structure-property relationship. Journal of Polymer Science Part B: Polymer Physics, 43, 3112-3126 (2005).

DOI: $10.1002 /$ polb.20596

[2] Petersson L., Oksman K.: Biopolymer based nanocomposites: Comparing layered silicates and microcrystalline cellulose as nanoreinforcement. Composites Science and Technology, 66, 2187-2196 (2006).

DOI: $10.1016 /$ j.compscitech.2005.12.010
[3] Ray S. S., Bousmina M.: Biodegradable polymers and their layered silicate nanocomposites: In greening the $21^{\text {st }}$ century materials world. Progress in Materials Science, 50, 962-1079 (2005).

DOI: $10.1016 /$ j.pmatsci.2005.05.002

[4] Zuiderduin W. C. J., Westzaan C., Huétink J., Gaymans R. J.: Toughening of polypropylene with calcium carbonate particles. Polymer, 44, 261-275 ( 2003). DOI: 10.1016/S0032-3861(02)00769-3

[5] Bartczak Z., Argon A. S., Cohen R. E., Weinberg M.: Toughness mechanism in semi-crystalline polymer blends: II. High-density polyethylene toughened with calcium carbonate filler particles. Polymer, 40, 23472365 (1999).

DOI: $10.1016 / \mathrm{S} 0032-3861(98) 00444-3$

[6] Zuiderduin W. C. J., Huétink J., Gaymans R. J.: Rigid particle toughening of aliphatic polyketone. Polymer, 47, 5880-5887 (2006).

DOI: $10.1016 /$ j.polymer.2006.05.077

[7] Lin Y., Chen H., Chan C-M., Wu J.: The toughening mechanism of polypropylene/calcium carbonate nanocomposites. Polymer, 51, 3277-3284 (2010). DOI: $10.1016 /$ j.polymer.2010.04.047

[8] Auras A., Lim L-T., Selke S. E. M., Tsuji H.: Poly(lactic acid): Synthesis, structures, properties, processing and applications. Wiley, New Jersey (2010).

[9] Zhou Q., Xanthos M.: Nanoclay and crystallinity effects on the hydrolytic degradation of polylactides. Polymer Degradation and Stability, 93, 1450-1459 (2008). DOI: $10.1016 /$ j.polymdegradstab.2008.05.014

[10] Jiang L., Zhang J., Wolcott M. P.: Comparison of polylactide/nano-sized calcium carbonate and polylactide /montmorillonite composites: Reinforcing effects and toughening mechanisms. Polymer, 48, 7632-7644 (2007).

DOI: $10.1016 /$ j.polymer.2007.11.001

[11] Chen C. C., Gang L. V., Pan C., Song M., Wu C. H., Guo D. D., Wang X. M., Chen B. A., Gu Z. Z.: Poly (lactic acid) (PLA) based nanocomposites - A novel way of drug-releasing. Biomedical Materials, 2, L1L4 (2007). DOI: $10.1088 / 1748-6041 / 2 / 4 /$ L01

[12] Iwatake A., Nogi M., Yano H.: Cellulose nanofiberreinforced polylactic acid. Composites Science and Technology, 68, 2103-2106 (2008). DOI: 10.1016/j.compscitech.2008.03.006

[13] Hapuarachchi T. D., Peijs T.: Multiwalled carbon nanotubes and sepiolite nanoclays as flame retardants for polylactide and its natural fibre reinforced composites. Composites Part A: Applied Science and Manufacturing, 41, 954-963 (2010). DOI: $10.1016 /$ j.compositesa.2010.03.004 
[14] Leu Y. Y., Mohd Ishak Z. A., Chow W. S.: Mechanical, thermal, and morphological properties of injection molded poly(lactic acid)/SEBS-g-MAH/organo-montmorillonite nanocomposites. Journal of Applied Polymer Science, 124, 1200-1207 (2012).

DOI: 10.1002/app.35084

[15] Liu S-P., Ying J-R., Zhou X-P., Xie X-L., Mai Y-W.: Dispersion, thermal and mechanical properties of polypropylene/magnesium hydroxide nanocomposites compatibilized by SEBS- $g$-MA. Composites Science and Technology, 69, 1873-1879 (2009).

DOI: $10.1016 /$ j.compscitech.2009.04.004

[16] Kusmono, Mohd Ishak Z. A., Chow W. S., Takeichi T., Rochmadi: Influence of SEBS-g-MA on morphology, mechanical, and thermal properties of PA6/PP/organoclay nanocomposites. European Polymer Journal, 44, 1023-1039 (2008).

DOI: $10.1016 /$ j.eurpolymj.2008.01.019

[17] González I., Eguiazábal J. I., Nazábal J.: Rubbertoughened polyamide 6/clay nanocomposites. Composites Science and Technology, 66, 1833-1843 (2006). DOI: 10.1016/j.compscitech.2005.10.008

[18] Bárány T., Czigány T., Karger-Kocsis J.: Application of the essential work of fracture (EWF) concept for polymers, related blends and composites: A review. Progress in Polymer Science, 35, 1257-1287 (2010). DOI: $10.1016 /$ j.progpolymsci.2010.07.001

[19] Wang H., Sun X., Seib P.: Strengthening blends of poly(lactic acid) and starch with methylenediphenyl diisocyanate. Journal of Applied Polymer Science, 82, 1761-1767 (2001).

DOI: $10.1002 / a p p .2018$

[20] Kim G-M., Michler G. H.: Micromechanical deformation processes in toughened and particle-filled semicrystalline polymers: Part 1. Characterization of deformation processes in dependence on phase morphology. Polymer, 39, 5689-5697 (1998).

DOI: $10.1016 / \mathrm{S} 0032-3861(98) 00089-5$
[21] Di Lorenzo M. L.: Calorimetric analysis of the multiple melting behavior of poly(L-lactic acid). Journal of Applied Polymer Science, 100, 3145-3151 (2006). DOI: 10.1002/app.23136

[22] Pan P., Inoue Y.: Polymorphism and isomorphism in biodegradable polyesters. Progress in Polymer Science, 34, 605-640 (2009).

DOI: $10.1016 /$ j.progpolymsci.2009.01.003

[23] Sarasua J-R., Rodríguez N. L., Arraiza A. L., Meaurio E.: Stereoselective crystallization and specific interactions in polylactides. Macromolecules, 38, 8362-8371 (1998). DOI: $10.1021 / \mathrm{ma} 051266 \mathrm{z}$

[24] Deshmane C., Yuan Q., Misra R. D. K.: On the fracture characteristics of impact tested high density polyethylene-calcium carbonate nanocomposites. Material Science and Engineering: A, 452-453, 592-601 (2007). DOI: $10.1016 /$ j.msea.2006.11.059

[25] Suksut B., Deeprasertkul C.: Effect of nucleating agents on physical properties of poly(lactic acid) and its blend with natural rubber. Journal of Polymers and the Environment, 19, 288-296 (2011).

DOI: $10.1007 / \mathrm{s} 10924-010-0278-9$

[26] Weon J-I., Gam K-T., Boo W-J., Sue H-J., Chan C-M.: Impact-toughening mechanisms of calcium carbonatereinforced polypropylene nanocomposite. Journal of Applied Polymer Science, 99, 3070-3076 (2006). DOI: 10.1002/app.22909

[27] Kusmono, Mohd Ishak Z. A., Chow W. S., Takeichi T., Rochmadi: Compatibilizing effect of SEBS-g-MA on the mechanical properties of different types of OMMT filled polyamide 6/polypropylene nanocomposites. Composites Part A: Applied Science and Manufacturing, 39, 1802-1814 (2008). DOI: 10.1016/j.compositesa.2008.08.009

[28] Collyer A. A.: Rubber toughened engineering plastics. Chapman and Hall, London (1994).

[29] Loyens W., Groeninckx G.: Deformation mechanisms in rubber toughened semicrystalline polyethylene terephthalate. Polymer, 44, 4929-4941 (2003). DOI: $\underline{10.1016 / \mathrm{S} 0032-3861(03) 00478-6}$ 